\title{
MIRANDA MARTINELLI MAGNOLI / PRODUÇÃO CIENTÍFICA
}

\section{MIRANDA MARTINELLI MAGNOLI / SCIENTIFIC PRODUCTION}

\section{Fany Galender}

Arquiteta, pesquisadora do LABQUAPÁ (Laboratório da Paisagem/Projeto Quadro do Paisagismo Brasileiro) e LABPARC (Laboratório Paisagem, Arte e Cultura) da FAUUSP.

E-mail:fgalender@uol.com.br 


\section{RESUMO}

Este texto é um registro dos trabalhos produzidos e/ou orientados pela Profa. Dra. Miranda Martinelli Magnoli ao longo de seus anos de docência junto da Faculdade de Arquitetura e Urbanismo da Universidade de São Paulo, destacando sua contribuição pioneira para o desenvolvimento da área de Paisagem e Ambiente no país. Foi organizado a partir de artigo publicado na Revista Paisagem Ambiente - Ensaios, n. 17, em 2003, com complementações e retificações.

\section{Palavras-chave: Pesquisa, ensino, paisagem, ambiente.}

\section{ABSTRACT}

This work is a register of Miranda Martinelli Magnoli's works during her period as professor of Landscape Architecture at Faculdade de Arquitetura e Urbanismo da Universidade de São Paulo, showing her contribution in the development of the Landscape Archuitecture and Design in Brazil.

Key words: Research, teaching, landscape, environment. 


\section{MIRANDA MARTINELLI MAGNOLI / PRODUÇÃO CIENTÍFICA}

\section{MIRANDA MARTINELLI MAGNOLI / SCIENTIFIC PRODUCTION}

Texto preparado a partir de artigo publicado na Revista Paisagem e Ambiente - ensaios, n. 17, em 2003, com complementações e retificações.

\section{PRODUÇÃO PÓS-GRADUAÇÃO}

\section{Magnoli, Miranda M. E. Martinelli}

Contribuição ao estudo dos espaços livres de uso público nos grandes aglomerados urbanos. 1973.

70 p. e dois volumes, em apêndice, compostos de 20 anteprojetos de paisagismo, um projeto completo e um levantamento de situação para instruir programa de projeto.

Tese (Doutorado).

É tese, para a época, imbuída de forte grau de questionamento; tem como pano de fundo o conjunto de experiências da prática profissional com a intensa agitação e crises (décadas de 1960/70), resultantes de extensas transformações sociais, políticas e econômicas em nível mundial e violentas mudanças institucionais do país; ao fundo a questão: como se daria a inserção da produção arquitetônica para uma sociedade de massas?

Na prática de participação de projetos e planos estavam: o primeiro levantamento e cadastramento de espaços livres municipais destinados a praças e parques em São Paulo, elaborado com Rosa Kliass em 1967/68; curso Town and Country Planning Course na Grã-Bretanha e Dinamarca, em 1968, na condição de bolsista da OEA e do British Council; participação no Plano Metropolitano de Desenvolvimento Integrado para São Paulo em 1969/70.

Na prática do ensino: a docência na FAU, como membro de equipes existentes - instrutora de Composição de Arquitetura em cátedra regida pelo professor arquiteto Abelardo Reidy de Souza (de 1960 a 1969); como auxiliar de ensino na disciplina Planejamento Urbano, na seqüência Planejamento Urbano e Territorial (de 1970 a 1972); nesse último ano, ainda com a condução do professor arquiteto Antonio Augusto de Azevedo Antunes, o programa previa conteúdos de Paisagismo, especialmente relacionados com os aspectos visuais, cromáticos e de vegetação, analisados a partir de exercícios de pequenos espaços urbanos. Um novo enquadramento teórico era questionado: inserir-se na abrangência do programa de planejamento territorial e urbano, compreender as questões contemporâneas em país de Terceiro Mundo e esclarecer-se do real papel em nosso país, dos movimentos ecológicos que emergiam nos países mais avançados. 
O texto aborda aspectos relacionados a:

1. A abordagem ecológica no planejamento paisagístico nas manifestações da época; resumemse considerações quanto à abordagem da natureza nos elementos mais diretamente relacionados com o processo de planejamento. Faz-se sucinta visão crítica do livro Design with nature, de McHarg, na ocasião recém-chegado ao Brasil.

2. Resumem-se dados bibliográficos sobre os efeitos da vegetação em relação ao ruído; à polvição do ar, ao microclima e à qualidade e quantidade da água. Aponta-se a insuficiência de conhecimentos científicos para abalizar as afirmações e proposições habitualmente utilizadas sobre os efeitos da vegetação na salubridade do meio.

3. A qualidade de vida no meio ambiente urbano; na época se iniciava compreensão mais correta do processo de urbanização em São Paulo em face da mercantilização do solo; os estudos posteriores em campos diversos aprofundaram o conhecimento da intensa e estratégica atividade comercial desenvolvida a partir do próprio solo. Levantava-se o papel das ruas enquanto pontos de encontro e convívio ante as peculiaridades do histórico da população; valorizavam-se as esquinas, os largos, as ruas de passagem de bondes; perguntava-se quais características espaciais deveriam ser privilegiadas e como os estudos sobre o comportamento humano em outros campos do conhecimento poderiam contribuir. Questionava-se a condução dos processos de planejamento em uso e a necessária interdisciplinaridade; a adoção dos espaços livres como espaços "verdes"; a difusão de idéias relacionando os parques ao "pulmão verde". $\bigcirc$ papel de "cheios" que os "vazios" urbanos deveriam assumir ainda era muito incipiente e, só posteriormente, passou a adquirir maior clareza entre os estudiosos da cidade e da paisagem urbana.

A bibliografia revela que, na época, a bibliografia estrangeira era quase a única disponível; os trabalhos nacionais no campo em que a autora se dedica eram em número reduzido; mesmo dentre os poucos indicados observa-se que são textos com enfoque fundamentalmente urbanístico e/ou artigos de revistas de divulgação.

Reis Filho, Nestor Goulart, orient.

\section{Magnoli, Miranda M. E. Martinelli}

Espaços livres e urbanização: Uma introdução a aspectos da paisagem metropolitana.

1982. 116 p. e quatro mapas da Grande São Paulo (evolução da urbanização; configuração: elementos de relevo e geologia; transportes coletivos aos parques; espaços livres (esc. 1:100.000)

Tese (Livre-docência).

Tendo por referência preliminar estudo da evolução do conceito de paisagem, o trabalho examina os aspectos fundamentais dos espaços livres em relação à urbanização. A distribuição dos espaços livres nas várias escalas do aglomerado metropolitano é analisada com apoio em extensa pesquisa efetuada na Grande São Paulo. São evidenciadas, como objetivo principal, as características da vinculação entre política metropolitana e política de espaços livres. Indicam-se diretrizes para programa de trabalho sobre os espaços livres da Grande São Paulo.

O levantamento de campo, coleta em entidades, levantamento fotográfico, organização de dados e tabulação e os mapas da Grande São Paulo se revelaram muito úteis, durante anos, para o ensino e para outros pesquisadores, na medida em que era o único material sobre espaços livres existentes para a Grande São Paulo. A pesquisa bibliográfica, já extensa e abrangente, em comparação a trabalho anterior de 1972, indicava os avanços que se haviam realizado na biblioteca da FAUUSP para a área. Ficaram delineadas algumas linhas básicas de critérios 
para o desenvolvimento de um "corpo" de pesquisas; um programa preliminar de investigações, cujos problemas eram relevantes no contexto da vida urbana, era iniciado para apoio às demais orientações.

Os quatro capítulos desenvolvem os seguintes aspectos:

1. Aspectos da paisagem: em quadros de blocos de acontecimentos históricos, faz-se uma leitura simultânea de síntese de reflexões e de síntese de levantamentos bibliográficos:

. evolução do conceito de paisagem;

- o legado conceitual e operativo.

2. O espaço livre, objeto de trabalho: analisam-se as configurações físicas nas escalas do lote à região:

. intervenção e presença do homem na paisagem;

- funções, temas e distribuição do espaço livre.

3. O contínuo do tecido urbano: aspectos decorrentes das pesquisas na escala urbana:

- o espaço livre da unidade habitacional;

- o espaço livre das habitações agrupadas;

- tecido urbano;

- espaços livres no tecido urbano implantados para convívio coletivo;

. espaços utilizados como "parques";

. transporte coletivo em ônibus.

4. Espaços livres da paisagem metropolitana: aspectos decorrentes das pesquisas na escala metropolitana; as influências das soluções nas escalas do lote e rua sobre a escala do espaço da região; os perímetros de contato do aglomerado urbano e dos grandes espaços livres internos; o desempenho do suporte ecológico e o espaço livre de funções que necessitam do aglomerado próximo ou são necessárias ao aglomerado:

- a estrutura espacial e o cotidiano;

- perímetros e urbanização, grandes espaços livres internos, polivalência;

. desempenho do suporte;

- condições do tempo.

\section{Orientações}

\section{Macedo, Silvio Soares}

Mutação de paisagem urbana: $\bigcirc$ bairro de Higienópolis e arredores.

$1982,3 \mathrm{v}$.

Dissertação (Mestrado).

Estudos da mutação da paisagem de uma área residencial da cidade de São Paulo - o bairro de Higienópolis e arredores, durante o período que se estende das últimas décadas do século XIX ao início dos anos 1980.

Caracterização da área de trabalho em seu entorno, na cidade, seu relevo, tipologias de paisagem no tempo e espaço.

Histórico de uma paisagem padrão - o desenvolvimento e evolução dos três tipos básicos identificados: 1884-1895; segmentos de paisagem urbana, as chácaras urbanizadas, em meio a 
elementos tipicamente rurais como campos, matas, etc. Formação, organização e parcelamento. Exemplos significativos; 1895-1940 - paisagem caracterizada pelo predomínio dos volumes baixos, casas em meio a jardins e quintais, implantados entre ruas largas e arborizadas.

Os diversos tipos de loteamento, os empreendimentos imobiliários - o moderno e o tradicional. Boulevard Bouchard - a exploração dos valores cênicos da paisagem, as áreas vizinhas surgidas como extensão a ele. Características gerais da paisagem, sua consolidação. Conjuntos paisagisticamente importantes e referenciais urbanos. O papel de sua principal via - a avenida Higienópolis, na cidade e no bairro - características; 1940 - paisagem caracterizada pelo predomínio de volumes altos, os edifícios de apartamentos implantados sobre a antiga malha urbana. As diversas fases de sua evolução, suas características em cada etapa. $\bigcirc$ arranha-céu como marco referencial e como elemento estruturador da paisagem. A perda de seus valores cênicos, o novo uso do solo, suas normas e influências na paisagem da área, o desaparecimento dos referenciais visuais e o surgimento de marcos preponderantemente funcionais - avenidas de muito trânsito, pontos comerciais, etc. Os elementos significativos antigos ainda existentes na paisagem - escolas, igrejas, etc.

Espaços livres de uso público - implicações do processo de mutação em sua configuração; espaços privados. As chácaras, seus parques e estrutura básica, tipologias de espaços e volumes do novo bairro - as residências de grande porte, sua forma de implantação. Os volumes construídos e seu papel na organização dos espaços; jardins de estilo, a paisagem composta, os quintais, seu uso e forma, os espaços resultantes da implantação dos arranha-céus nos antigos lotes. Tipologia básica dos volumes construídos, sua relação com os novos padrões de jardim a pátios. A implantação do edifício e o sítio.

Espaços públicos-ruas, características espaciais e de uso, arborização. Introdução a alguns tipos básicos de vias, estudo de casos, seus espaços e articulações com o meio; vilas e vielas - como casos especiais, sua formação, tipificação e implantação; praças - localização, evolução e organização básica, tipologias encontradas formas, de uso, seu papel na área de estudo.

\section{Nishikawa, Ayako}

Espaços livres junto às habitações em São Paulo: Estudo de casos de apropriação do espaço da rua articulado ao seu entorno habitacional.

1984.

\section{$215 \mathrm{p}$.}

Dissertação (Mestrado).

O objetivo deste trabalho é o estudo da dinâmica de uso dos espaços livres de grande potencialidade por sua própria natureza - a contigüidade habitacional. Tratam-se de espaços complexos, imbuídos de significação conferida pela própria dialética da vida, em seu contínuo deslocar e permanecer, tendo como ponto de partida e chegada a habitação.

Portanto, fica explícito o fato de as relações espaciais decorrentes extrapolarem o âmbito da localidade de nosso estudo, que para efeito deste trabalho ficou limitado ao espaço livre da rua, articulado aos espaços de seu entorno residencial imediato.

Este estudo foi conduzido a partir do estabelecimento de uma perspectiva teórica, com base nos conceitos correntes de autores conhecidos e permitindo-nos elaborar as definições taxionômicas dos tipos de espaços que comparecem neste trabalho, adequando-as à finalidade do mesmo.

O referencial teórico consiste em que o desempenho de um espaço depende das inter-relações entre as configurações dinâmicas do suporte e das formas de seu uso. Este, por sua vez, está 
estreitamente relacionado às necessidades e às aspirações do usuário, condicionado às suas características intrínsecas e extrínsecas ou conjunturais.

trabalho foi desenvolvido com base na pesquisa realizada em 94 áreas selecionadas.

As conclusões a que chegamos permitiram enumerar alguns critérios básicos para o desenho dos espaços similares.

\section{Sun, Alex}

Água e paisagem: Questões de paisagismo em torno de um reservatório de abastecimento na Grande São Paulo.

1985

$97 \mathrm{p}$.

Dissertação (Mestrado).

A água sintetiza na paisagem a idéia de dinâmica, continuidade e unidade. Bacias hidrográficas, unidades territoriais naturais da água, delimitam paisagens circunscritas a um sistema hídrico. Intervenções antrópicas como reversão e adução de rios alteram os limites da água e da paisagem. Um projeto de paisagismo relacionado à água deve reconhecer três unidades de atuação caracterizadas por bacias hidrográficas, o espaço envolvente e o conjunto terra-água.

○ estudo adota o reservatório de Juqueri em Mairiporã para discutir as múltiplas escalas necessárias para se compreeender aquela água represada e as paisagens envolventes. Parte da água do Juqueri vem de outras bacias fora da região metropolitana de São Paulo, e, no entanto, o reservatório e seu espaço envolvente formam uma unidade coesa e marcante na paisagem. Para assegurar a qualidade da água para o abastecimento, exige-se, na escala voltada para o projeto, um desenho voltado a um monitoramento constante.

\section{Abbud, Benedito}

Vegetação e projeto: Estudos de caso em São Paulo, com as reflexões de um arquiteto.

1987.

359 p.

Dissertação (Mestrado).

Este trabalho é uma introdução ao processo de uso e escolha da vegetação em projetos de paisagismo de escala local. Aborda a vegetação do ponto de vista do arquiteto como um dos elementos organizadores do espaço, da paisagem urbana.

Considera o vegetal em todo o processo do projeto, procurando tirar partido de suas potencialidades plásticas e arquitetônicas.

Examina as várias fases deste processo, tendo com referência estudos de caso em que a organização dos espaços e subespaços pela vegetação é questão central. São três os estudos de caso, de dimensões e condicionantes variadas, de uso público e particular, relacionados com espaços internos ou não, para mostrar as diferenças no processo do projeto, que vão desde o levantamento dos dados iniciais até a escolha das espécies e sua manutenção.

O desenho da paisagem pela organização dos espaços é parte da formação do arquiteto; assim este trabalho se destina principalmente a alunos de escolas de arquitetura. Procura utilizar uma 
redação sem jargões, compatível com o "mundo dos estudantes", privilegiando a linguagem gráfica sempre que possível.

\section{Lima, Catharina Pinheiro Cordeiro dos Santos}

Paisagem em metamorfose: A cidade de Natal.

1987.

159 p.

Dissertação (Mestrado).

É um estudo sobre paisagem urbana. Faz uso da cidade de Natal para observar as relações entre as manifestações humanas e as bases naturais. As singularidades do sítio fazem emergir a necessidade de análise de duas escalas de trabalho: a do suporte, que extrapola os limites administrativos do município e a do urbano propriamente dito. Identificar os aspectos essenciais que relacionam o fato urbano às peculiaridades do sítio é a chave para compreensão da paisagem. Nesse entendimento do papel fundamental das relações é que se permite abordagem ainda preliminar dos principais componentes das bases naturais e da intervenção antrópica. Essa abordagem leva em conta a geologia, águas superficiais e subterrâneas, geomorfologia e cobertura vegetal, em suas formas associativas (dunas, praias, manguezais, estuário, ambientes lagunares) e o assentamento humano em suas figuras de espaços identificados e livres de edificação. Essas relações explicam a atual tendência de atividade turística; estas carregam consigo transformações intensas nos rumos de ocupação do solo. A evolução urbana deverá planejar a inovação funcional que se opera contemporaneamente.

\section{Pellegrino, Paulo Renato Mesquita}

Paisagem e ambiente: $O$ processo de aproximação no setor oeste da macrometrópole de São Paulo.

1987.

$113 \mathrm{p}$.

Dissertação (Mestrado).

No trabalho é levantado, em uma primeira aproximação, um modo de projetar o ambiente humano em uma macroescala, a partir de uma reflexão atenta ao funcionamento ambiental e de sua expressão no conceito holístico da paisagem. $\bigcirc$ seu objeto de estudo, definido pela triangulação São Paulo-Campinas-Sorocaba, sofreu um processo de conhecimento que se inicia pelo referencial teórico dado pela totalidade dos sistemas ecológicos, e continua em uma análise de seus componentes naturais (geomorfologia, clima, vegetação, etc.) e antrópicos (enquanto somatório das estruturas da história da ocupação do espaço, mais os impactos relevantes que estão sendo gerados). Conclui o ciclo uma síntese paisagística elegendo parâmetros para a predição de conseqüências e escolhas, definidas por unidades de paisagem, que, valoradas, formam a base de uma programação global.

\section{Bartalini, Vladimir}

Praças do metrô: Enredo, produção, cenário, atores.

1988. 
269 p.

Dissertação (Mestrado).

O trabalho visa pôr em discussão a finalidade e o desempenho dos espaços livres públicos nas estações do metrô de São Paulo.

Parte de considerações gerais sobre os espaços livres públicos centrais e subcentrais para, em seguida, deter-se na análise dos 15 casos que, até o momento, compõem o conjunto das "praças" criadas ou transformadas pela implantação das estações.

O estudo procura cobrir os diversos fatores que intervêm no projeto e no uso dos espaços livres, agrupando-os em categorias designadas como enredo, produção, cenário e atores.

A partir da avaliação dos casos visa contribuir para o aperfeiçoamento das atividades profissionais e de ensino voltadas aos espaços livres públicos.

\section{Franco, Maria de Assunção Ribeiro}

Espaço livre e arquitetura: $O$ projeto dos espaços livres junto dos edifícios bancários. 1989.

204 p.

Dissertação (Mestrado).

Este trabalho apresenta como preocupação essencial a relação entre os cheios e vazios da arquitetura, apresentando-a como dialética constante entre o positivo e o negativo que, ao materializar-se no espaço, evidencia em sua semiótica toda a gama de valores e atitudes de uma cultura perante si mesma e perante o mundo.

A relação entre o fora e o dentro, sempre presente em qualquer assentamento antrópico, tornase mais significante quando o vazio, o fora, adquire características de jardim, palavra que traz consigo o valor arquetípico de lugar sacro ou paraíso e, portanto, carrega na gênese de seu deslocamento, do bosque fora da cidade para o parque ou pequeno espaço ajardinado intraurbano, a força de seu primitivo simbolismo.

No século XX, em São Paulo, o jardim sai do entorno residencial e dos espaços públicos para o círculo dos estabelecimentos comerciais, especialmente dos shopping centers e dos bancos.

\section{Mariano, Cassia Regina}

Parques metropolitanos de São Paulo: Subsídios para o desenho.

1992.

$218 \mathrm{p}$.

Dissertação (Mestrado).

Estuda-se o desenho em parques metropolitanos de São Paulo: são espaços públicos do contexto urbano. Abordam-se legados de Inglaterra, França e Estados Unidos desde a instituição do parque público em meados do século XVIII. Analisam-se dois estudos de caso: Parque Ibirapuera e Parque Ecológico do Tietê. $\bigcirc$ primeiro implantado em 1954, reflete novos valores culturais que vêm no bojo da ampla transformação ocorrida em São Paulo desde a década de 1920. O Parque Ecológico do Tietê, projetado após a institucionalização da região metropolitana, insere o desenho do parque na questão do tratamento do rio Tietê para efeito de preocupação 
de enchentes, reportando-se a todos os planos elaborados desde meados do século XIX. $O$ desenho dos parques é situado em um quadro sobre os antecedentes históricos quanto à paisagem e flora brasileiras.

\section{Santos, Emmanuel Antonio dos}

Indústria e paisagem, a evolução urbano-industrial e a transformação da paisagem: $O$ caso de São José dos Campos.

1993.

$178 \mathrm{p.}$

Dissertação (Mestrado).

Pretende mostrar a morfologia da paisagem, como resultante das relações entre antropização e suporte físico, em situação com preponderância da produção urbano-industrial. São tomados como pressupostos o entendimento da paisagem em seu aspecto mais geral de resultante da antropização sobre o suporte físico e as configurações - desenhos - resultantes. São selecionados, portanto, como condicionantes da configuração da paisagem: as especificidades de morfologia do sítio; o porte, localização e distribuição da urbanização e o porte, localização e distribuição espacial no tecido urbano das instalações industriais. E selecionado como estudo de caso um dos municípios do interior do estado de São Paulo, que reúne elementos-chave para o estudo e a compreensão do que chamamos de paisagem urbano-industrial.

\section{Queiroga, Eugenio Fernandes}

A produção da paisagem habitacional metropolitana: Três estudos de caso no município de Osasco - SP.

1994.

$274 \mathrm{p}$.

Dissertação (Mestrado).

Em São Paulo, a paisagem habitacional ocupa a maior extensão territorial e melhor exprime o modo de vida urbano. $\bigcirc$ ambiente resultante é questionável. $\bigcirc$ entendimento de suas causas pode auxiliar para a criação de situações mais adequadas. Esta dissertação investiga os determinantes do processo de produção de paisagens habitacionais na metrópole de São Paulo. Escolheram-se três bairros, no município de Osasco, representativos da atualidade metropolitana - condomínios horizontais fechados, loteamentos de periferia e áreas em processo de verticalização. Verificou-se o papel das diferentes instâncias (cultura, economia, estado e suporte físico) em diversos modos de produção habitacional - casa por encomenda, casa autoconstruída e habitação para o mercado. Avaliaram-se criticamente tais processos e seus resultados no âmbito da paisagem, ambiente e uso social do espaço. Os diversos modos de produção habitacional são determinantes nas diferenças das paisagens em que cada um deles predomina. A baixa qualidade da paisagem e ambiente é o traço comum aos casos estudados; decorre, principalmente, de um fator de ordem cultural-ideológica que valoriza a vida privada e desqualifica a res-publica, aí inclusa a paisagem e o ambiente. 


\section{Sandeville Júnior, Euler}

Herança da paisagem.

1994.

239 p.

Dissertação (Mestrado).

É uma reflexão sobre o projeto da paisagem, as maneiras como vem sendo entendido e a busca de caminhos para a atuação, que incluam uma indagação constante perante a cidade e a cultura. São três módulos de análise: a) paisagismo: procura-se reconstituir os nexos conceituais, estéticos, interpretativos do projeto da paisagem com a cidade, o urbanismo, a arquitetura, a arte. Mostra-se a complexidade e a interação conceitual, social e estética do projeto da paisagem, investigando como essa herança do desenho se enraíza profundamente em nossa cultura; b) arquitetura: investiga-se a inserção da arquitetura na cidade como fato distintivo, como projeto de modernização do espaço público. Dois pontos são fundamentais: o papel do poder público e do arquiteto na configuração da cidade e o conceito de seu projeto arquitetônico-urbanístico; c) gestão: prejuízos e desperdícios materiais e culturais decorrem da falta de intencionalidade com que o poder público administra o espaço urbano. Mostra-se a necessidade de uma gestão da paisagem, baseada em critérios valorativos e integrativos das ações dos diversos agentes e na indagação constante perante a cidade e a cultura.

\section{Lima, Catharina Pinheiro Cordeiro dos Santos}

A natureza na cidade, a natureza da cidade.

1997.

204 p.

Tese (Doutorado).

O momento contemporâneo requer uma reavaliação das percepções, valores e papéis da sociedade em sua relação com a natureza, para fazer face à crise ambiental na qual nos encontramos imersos. $\bigcirc$ grau de complexidade dessa crise invalida quaisquer abordagens reducionistas ou fragmentadas, demandando, ao contrário, a inserção dos múltiplos aspectos que compõem a vida moderna, em uma perspectiva abrangente. Nesse processo de transformação cultural, o Paisagismo pode contribuir como uma disciplina inclusiva, capaz de dar visibilidade aos novos esforços de síntese. Pretende-se, à luz da história, uma reflexão sobre os processos que deram origem aos trabalhos de Paisagismo, almejando a proposição de novos paradigmas que possam vir a nortear o projeto da natureza no ambiente urbano.

\section{Chermann, Davi}

Jogos de linguagem: Recortes analógicos e digitais.

1998.

1 v., p. 186. + CD-ROM.

Dissertação (Mestrado).

Estudam-se as tecnologias da informação aplicadas à arquitetura no aspecto referente aos procedimentos e técnicas da representação da linguagem digital e do meio digital utilizadas para o projeto em arquitetura e urbanismo. A fundamentação teórica recorta as últimas décadas desse 
século em seus avanços na ciência e tecnologia com os rebatimentos no pensamento arquitetônico. Identificam-se as transições na representação do projeto desde a prancheta eletrônica, a maquete eletrônica, o CAD paramétrico até o ambiente digital, destacando-se as mais recentes reflexões sobre a nova arquitetura. A leitura do trabalho envolve um pensamento básico de interferência dos procedimentos de representação sobre o processo criativo do projeto. É apresentado utilizando as técnicas atuais da informática em uma linguagem digital capaz de permitir a comunicação, transmissão e por conseguinte o compartilhamento do saber.

\section{Sandeville Júnior, Euler}

As sombras da floresta: Vegetação, paisagem e cultura no Brasil.

1999.

\section{$371 \mathrm{p}$.}

Tese (Doutorado).

Este trabalho investiga a vegetação em sua apropriação pelos desígnios e saberes humanos enquanto elaboração da cultura, discutindo o jogo entre a construção da idéia de natureza selvagem e da identidade no caso brasileiro. A organização da pesquisa se dá da seguinte forma: uma polarização entre apreciação estética (fundamento da criatividade artística) e investigação científica da natureza; uma leitura de aspectos históricos da cultura da apreciação e da relação com a vegetação tropical.

\section{Lima, Zeuler Rocha Mello de Almeida}

A cidade como espetáculo: $\bigcirc$ arquiteto no paradoxo da estetização da cultura contemporânea. 2000.

$286 \mathrm{p}$.

Tese (Doutorado).

Este trabalho investiga as transformações nas formas de representação da cidade contemporânea, de sua paisagem arquitetônica e de seus espaços públicos, e como elas se relacionam com as condições de trabalho e com o imaginário do arquiteto. As teorias e as práticas críticas ao modernismo racionalista na arquitetura e no urbanismo acabaram desembocando contemporaneamente em um paradoxo. Sob pressão da estetização cultural e da reestruturação econômica nas práticas do capitalismo globalizante desde os anos 1970, as abordagens pós-modernas passaram, frequentemente, da resistência à celebração da lógica neoliberal de produção do espaço. Apresentamos o modelo da cidade, como espetáculo, como a epítome desse paradoxo. $\bigcirc$ espetáculo tem crescentemente sustentado as práticas recentes de revitalização de áreas urbanas históricas e de criação de pólos de desenvolvimento urbano, entre as quais apontamos os exemplos de Detroit e de São Paulo. Propomos analisar esse fenônemo em face das transformações econômicas, culturais e sociais contemporâneas e ante a crise mais ampla da modernidade, assim como apresentar possibilidades teóricas de continuidade ao esforço crítico no pensamento e na prática da arquitetura. 


\section{Chiesa, Paulo}

O desenho como desígnio: Por uma ética do risco.

2001.

$500 \mathrm{p}$.

Tese (Doutorado).

A partir de uma experiência didática coordenada pelo autor em sua escola - o Ateliê UIA 1996, o ensino do projeto em arquitetura começou a ser discutido. Isso aconteceu na Universidade Federal do Paraná, no curso de Arquitetura e Urbanismo, entre 1995 e 1996. Partiu-se da idéia que arquitetura é a arte e a técnica de projetar e construir espaços úteis à sociedade, e ainda, é capaz de articular e integrar os conhecimentos sobre edifícios, cidades e paisagens em um todo complexo e interdependente, subentendido no conceito de ambiente. A proposta também estabelece que se aprende arquitetura desenhando-a, e, portanto, o processo de desenho sintetiza o método específico da disciplina. Por outro lado, defende-se a particular visão que a escola estrutura e planeja o processo de ensino e aprendizagem a partir da realidade física e social do ambiente no qual ele se insere. Nesse caso, a problemática da região metropolitana de Curitiba é tomada como referência para o exercício de projeto, tanto alimentando as estratégias de ensino e aprendizagem como desenhando o perfil do profissional formado nessa escola. O foco central da análise dirige-se ao processo de transmissão cultural feito pela escola e pelo professor - destacando o papel original e criativo de ambos na construção das disciplinas acadêmicas. As noções de cultura - cultura da escola e de saber docente e discente - são utilizadas para refletir sobre a tradição brasileira no ensino de projeto e para sistematizar o Ateliê UIA 96. A investigação se concentra nas últimas cinco décadas do século XX, período marcado por intensas transformações no modo de vida dos brasileiros e do ambiente em geral. Uma fase expressiva da moderna arquitetura brasileira, na qual foram desenvolvidos os modelos de escola e ensino de arquitetura de nosso país, incluindo o do CAUUFPR. $O$ estudo desse panorama histórico objetivou investigar a existência ou não de uma doutrina de projeto, gerada no entrelaçamento da trajetória do CAUUFPR e da arquitetura na cidade de Curitiba. Essa tese sustenta que o ensino superior de arquitetura deve ser considerado como um trabalho social específico e exigente, tanto do ponto de vista ético quanto profissional. As suas conclusões incluem a discussão da proposta de ensino de projeto integrado em arquitetura, assim como a do programa de ensino desenvolvido na disciplina de Estudos da Forma, ministrada no primeiro ano da CAUUFPR. $\bigcirc$ resultado final é, portanto, a argüição e defesa de uma disciplina acadêmica orientada pelos pressupostos defendidos nessa tese e pelas atuais diretrizes curriculares do curso de Arquitetura e Urbanismo da UFPR.

\section{Santos, Emmanuel Antonio dos}

As paisagens do plano e os planos da paisagem: Da paisagem no planejamento ao planejamento com a paisagem.

2002.

$206 \mathrm{p}$.

Tese (Doutorado).

O presente trabalho pretende contribuir para a discussão das questões relativas ao planejamento urbano e em especial à elaboração de planos diretores. Entende-se que a efetiva e concreta incorporação dos elementos do meio natural ou com relativo grau de naturança, no processo de pensar o planejamento urbano e de promover a urbanização, pode efetivamente contribuir 
para a obtenção de um meio urbano mais equilibrado, mais justo, mais diversificado no uso dos recursos da natureza dos/nos espaços, com paisagens mais integradas e integradoras e de maior qualidade de desenho dos espaços, especialmente aqueles de uso público. As populações de menor poder aquisitivo são aquelas que mais ficam prejudicadas em face dos problemas decorrentes da falta de integração entre os processos naturais e os processos urbanos; é sobre elas que também recai o ônus maior da carência e desqualificação dos espaços livres públicos.

Pretende-se, à luz de uma experiência concreta na elaboração de plano diretor, expor uma reflexão sobre os processos de elaboração de planos e proposições de planejamento. Entende-se que os processos de mudança no planejamento e intervenção se dão a partir da realidade presente na sociedade; esta, atualmente, já inclui a questão ambiental; sua problemática é parte das alternativas do projeto de mudança. $\bigcirc$ enfoque e, conseqüentemente, a abordagem, visa contribuir na busca das alternativas, ao incorporar, de fato, a paisagem na prática do planejamento.

\section{Sun, Alex}

Convívio e exclusão no espaço público: Questões de projeto da praça.

2004.

$271 \mathrm{p}$.

Tese (Doutorado).

foco desse trabalho é projeto de praças como lugares de convívio social cotidiano e elementos essenciais de articulação do tecido urbano. Desenvolvido predominantemente nos Estados Unidos, o paisagismo moderno enfatizou, ao longo do século XX, o uso do espaço livre público para recreação, esportes, melhoria do ambiente urbano e preservação de recursos naturais, sempre como antídotos da vida urbana densa e diversificada e em favor dos domínios privado, vicinal ou semipúblico sobre o público. Radicalmente oposta, a praça, urbana por definição, é um espaço público da prática da vida pública. Praça, uma instituição latina por excelência, faz parte da formação de nossas cidades e de nossa cultura popular. Seis praças da área central de São Paulo, representativas de projetos realizados nas últimas seis décadas, foram analisadas e comparadas sob os aspectos de uso e de inserção no tecido urbano. As praças mostraram variações de tamanho, delimitação, layout, mobiliário urbano, tratamento de borda e acessos. Os resultados permitiram concluir: a) desvinculação entre as praças e os entornos; b) ausência de manutenção e adaptação sistemáticas; c) domínio do "urbanismo" viário e da engenharia de tráfego; d) ênfase no design ou jardinagem em detrimento do convívio.

\section{Coelho, Ana Maria Antunes}

O outro lado da rua.

2004.

$206 \mathrm{p}$.

Tese (Doutorado).

As calçadas representam grande potencial do espaço público, mas em função de sua fragmentação, deixam de ser compreendidas como espaço essencial da vida urbana. Isso cria um distanciamento entre a forma pela qual são abordadas nos meios técnicos e pelo poder público e aquela em que acontecem na realidade e no cotidiano da cidade. Para reduzir esse distanciamento, é necessária sua valorização em cada contexto, nas várias escalas e formas de intervenção que influenciam em sua configuração e apropriação. Por meio de abordagens 
diferenciadas, em recortes e escalas, procuramos evidenciar um panorama, no qual as calçadas são analisadas como protagonistas do espaço urbano, ressaltando tanto a diversidade de usos e apropriações como também procurando compreender os vários elementos que interferem em seu caráter, identificando possibilidades de valorizá-las. Consideramos que essa valorização sob a perspectiva do projeto arquitetônico e urbanístico está vinculada à valorização do próprio homem como elemento fundamental no contexto urbano e à interdependência das escalas de abordagem, com o estreitamento do diálogo entre poder público, meio técnico e usuários. $\mathrm{Na}$ tentativa de abranger esses agentes, utilizamos a experiência do plano diretor para a cidade de São Paulo de 2002/2003, no qual pudemos presenciar o imbricamento dessas três instâncias, destacando, neste trabalho, aqueles aspectos os quais consideramos relevantes e que possam contribuir para novas posturas de projeto, valorizando a concepção e apropriação do espaço público.

\section{Silva Filho, Carlos Alberto da}

Proteção e fomento da vegetação no município de São Paulo: Possibilidade, alcance e conflitos. 2005.

227 p.

Tese (Doutorado).

O município de São Paulo localiza-se em terrenos de uma bacia sedimentar de relevo colinoso, cercada por morros e serras do embasamento cristalino e drenada por $3.200 \mathrm{~km}$ de cursos d'água. Sobre esses terrenos pouco férteis, à exceção das várzeas, desenvolvia-se uma vegetação diversa, formada por matas de terra firme e de galeria; brejos e campos naturais. Essa cobertura vegetal vem seguindo um processo contínuo de redução, de fragmentação e de alteração de sua composição florística. Figura cada vez mais como elemento periférico ou como enclave do tecido urbano, diminuindo sua capacidade de auto-sustentação e de sustentação de fauna expressiva, e diminuindo o contato diário das pessoas com elementos e processos naturais. Tal processo se realiza a despeito de um conjunto de normas legais federais, estaduais e municipais e de acordos internacionais que buscam preservar porções significativas dessa vegetação e criaram possibilidades para a inserção e a manutenção da vegetação no tecido urbano e, por conseqüência, para que mais natureza permeie esse tecido. Comparando-se estudos realizados de 1911 a 2002, observa-se uma simplificação da composição da vegetação e uma grande redução em sua extensão, embora fragmentos significativos possam ser encontrados. A eficácia da legislação não foi ampla, mas pontual. Fatores de diferentes ordens, como estrutura e organização da administração pública inadequadas para a efetivação dos instrumentos de proteção e fomento adotados pela legislação; falta de capacitação para atividades específicas e falta de responsabilização por danos ao meio ambiente dos servidores públicos; conflitos oriundos de diferentes interpretações da legislação e falta de interesse da administração pública para sanar tais conflitos contribuem para a ineficácia da legislação. As evidências apontam, no entanto, que tais fatores são causas secundárias; a causa primeira para a não-materialização plena das possibilidades de inserção e manutenção da vegetação no tecido urbano é o conflito com os interesses do setor, imobiliário ou das frações desse setor, comprometidas unicamente com maior lucratividade de seus empreendimentos. Os insucessos da proteção e do fomento da vegetação resultam de um embate desigual e malsucedido com os interesses do setor imobiliário no processo de construção do espaço urbano. A desestruturação dos órgãos da administração pública e os conflitos entre esses órgãos não são casuais nem estão desconectados; são conseqüências da prevalência dos interesses do setor imobiliário, ou de frações deste, sobre os interesses públicos, que impedem a plena materialização das potencialidades da legislação de proteção e fomento da vegetação. 